\title{
Reinforcement of poly(dimethylsiloxane) by sol-gel in situ generated silica and titania particles
}

\author{
L. Bokobza*, A. L. Diop \\ Laboratoire PPMD, E.S.P.C.I., 10 rue Vauquelin, 75231 Paris Cedex, France
}

Received 1 March 2010; accepted in revised form 10 April 2010

\begin{abstract}
The usual sol-gel process was applied to precipitate silica or titania particles in a preformed poly(dimethylsiloxane) (PDMS) network under the presence of dibutyltin diacetate used as a catalyst. The resulting structures of the reinforcing fillers were studied by transmission electron microscopy and small-angle neutron scattering. Stress-strain measurements in elongation and equilibrium swelling experiments revealed distinct behaviors mainly attributed to the nature and the size of the generated particles and to the formation, in the case of titania, of a filler network even at low filler loadings.
\end{abstract}

Keywords: nanocomposites, reinforcement, poly(dimethylsiloxane), silica, titania

\section{Introduction}

In the unfilled state, poly(dimethylsiloxane) (PDMS) elastomers have generally poor mechanical properties which can be greatly improved by incorporation of mineral particles. Uniformity of the dispersion and good interfacial adhesion between the matrix and the filler have a strong influence on the performance of the elastomeric material. PDMS is traditionally reinforced with silica and the interaction between the two phases is ensured via hydrogen bonds between the silanols on the silica surface and the oxygen atoms of the polymer chains. Although fillers can be incorporated by the usual technique of blending them into the polymer before cross-linking, a number of alternative novel techniques for incorporation of fillers have been developed. They include a sol-gel process to precipitate particles into the elastomeric matrix. This process produces a finely divided morphology of filler resulting in optically transparent materials. The formation of the inorganic component is carried out under mild synthetic conditions and involves various alkoxides $\left(\left[\mathrm{M}(\mathrm{OR})_{\mathrm{x}}\right]\right.$, where $\mathrm{M}=\mathrm{Si}, \mathrm{Ti}, \mathrm{Zr}$, $\mathrm{Al} \ldots$ and $\mathrm{R}$ is an aliphatic group) that are hydrolyzed and condensed under either acidic or basic catalysis, in order to form $\mathrm{M}-\mathrm{O}-\mathrm{M}$ bridging units.

A series of previous investigations [1-7] has shown the feasibility of precipitating silica, titania or mixed silica-titania phases into PDMS networks. All these studies report significant property improvements in the hybrid composites with regard to the unfilled networks.

Although there are a number of ways to carry out the sol-gel technique to prepare hybrid organic composites, the method chosen in this paper is to synthesize the mineral phase in already crosslinked networks by using a synthetic protocol different from those previously reported in the literature. Additionally, the sol-gel approach developed for the in situ generation of silica into an elastomer is extended to the generation of titania by hydrolyzing a titanate instead of a silicate. PDMS networks filled with in situ generated reinforced particles are 
prepared and characterized through their morphological, mechanical and swelling properties in order to compare titania-filled materials with those filled with silica.

\section{Experimental}

\subsection{Materials}

PDMS having hydroxyl chain ends and a numberaverage molecular weight of $18000 \mathrm{~g} \cdot \mathrm{mol}^{-1}$ was obtained from Gelest (Morrisville, PA, USA). The catalysts: stannous-2-ethyl-hexanoate for the crosslinking reaction and dibutyltin diacetate for the solgel process were respectively supplied by Sigma and Aldrich. The alkoxides, tetraethoxysilane (TEOS) and titanium n-butoxide (TBO) were provided by Gelest (Morrisville, PA, USA) and Acros Organics (Geel, Belgium), respectively. All of these materials were used as received.

\subsection{Synthetic aspects}

In this study, unfilled PDMS networks are first prepared and are then swollen in the adequate alkoxide.

\subsubsection{Preparation of the unfilled PDMS networks}

The unfilled networks are prepared from hydroxyterminated PDMS by end-linking reactions using tetraethoxysilane (TEOS) as the cross-linking agent. In this method of network synthesis, a stoichiometric balance between ethoxy groups of the tetrafunctional alkoxysilane cross-linker and the hydroxyl chain ends of the hydroxyl-terminated PDMS precursor chains, should be required to get model networks characterized by constant junction functionality and known molecular weight between crosslinks (close to the number-average molecular weight of precursor chains) [1, 2, 8-12]. Actually, networks prepared at stoichiometric conditions have an elastic modulus lower than that deduced from the molecular weight between cross-links and great soluble fraction (around 10\%). This may be due to the volatility of TEOS thus reducing the amount of cross-linker required for the alkoxyfunctional condensation reaction. Much greater ratios of cross-linker functions to chain ends than that required by stoichiometry have already been used in the literature $[13,14]$ but a systematic study of the effect of excess of TEOS on the mechanical properties of networks synthesized from $\mathrm{OH}$-terminated chains shows that a $50 \%$ excess (and not higher values as already reported) are enough to ensure correct modulus and reasonable soluble fraction. So, hydroxyl-terminated PDMS ( $M_{w}=$ 18000 ) is mixed for half an hour with TEOS, in excess of 50\%. A small amount of stannous-2ethyl-hexanoate used as catalyst, is then added to the mixture under mechanical stirring just for 5 minutes to avoid cross-linking reaction during mixing. The reacting mixture is slowly cast into a Teflon mold and left for a few minutes at room temperature then at $80^{\circ} \mathrm{C}$ for one day for complete curing. The films are extracted with toluene for 72 hours to remove any unreacted materials. The sol fractions are between 4 and $5 \%$.

\subsubsection{Preparation of the in situ filled PDMS networks}

The next step for composite preparation involves swelling the unfilled extracted polymer network in a silicon alkoxide for silica or in a titanium alkoxide for titania generation. The inorganic precursor is TEOS for silica and titanium n-butoxide (TBO) for titania. In fact, titanium alkoxides have much higher reactivity than silicon analogues and the resistance to hydrolysis can be obtained by increasing the length of the alkyl chain [15]. Therefore, as in other studies $[16,17]$ titanium n-butoxide (TBO) has been chosen as the precursor of $\mathrm{TiO}_{2}$ in the solgel process.

The two overall reactions can be summarized as shown in Equations (1) and (2):

$$
\begin{aligned}
& \mathrm{Si}\left(\mathrm{OC}_{2} \mathrm{H}_{5}\right)_{4}+2 \mathrm{H}_{2} \mathrm{O} \rightarrow \mathrm{SiO}_{2}+4 \mathrm{C}_{2} \mathrm{H}_{5} \mathrm{OH} \\
& \mathrm{Ti}\left(\mathrm{OC}_{4} \mathrm{H}_{9}\right)_{4}+2 \mathrm{H}_{2} \mathrm{O} \rightarrow \mathrm{TiO}_{2}+4 \mathrm{C}_{4} \mathrm{H}_{9} \mathrm{OH}
\end{aligned}
$$

For in situ precipitation of filler particles, the PDMS films are swollen in the alkoxide (TEOS or TBO) in the presence of a $\mathrm{pH}$-neutral catalyst: dibutyltin diacetate (DBTDA) used at 3 weight percent. The swelling time determines the degree of alkoxide absorption and thus the filler loading. Both the swollen film and a beaker containing water are placed for 48 hours into a desiccator maintained at a constant temperature $\left(30^{\circ} \mathrm{C}\right)$ thus exposing the swollen film to saturated water vapor. 
The film is then vacuum-dried at $80^{\circ} \mathrm{C}$ for several days to constant weight in order to remove any alcohol generated from the reaction and also the remaining alkoxide which has not been hydrolyzed. The amount of filler incorporated into the network was calculated from the weights of the films before and after the generation of the filler. As a result of lower viscosity, the rate of diffusion of TEOS is much faster than that of TBO in PDMS films, leading, at a given swelling time, to a much higher swelling ratio. As a typical example, a degree of swelling of $100 \%$ of the initial PDMS film requires a swelling time of about $10 \mathrm{~min}$ in TEOS and $1000 \mathrm{~min}$ in TBO.

Infrared spectroscopy has been used to follow the sol-gel process. In particular, we note a progressive reduction in intensity of absorption bands associated with the alkoxides during the hydrolysis process and a total disappearance of these bands after total reaction. On the other hand, silica formation within the preformed PDMS network can be followed in the infrared spectra of the silica-filled PDMS networks where it is seen that the bands associated with silica increase with the silica content in the composite

\subsection{Characterization techniques}

For the transmission electron microscopy (TEM), ultrathin sections were cryomicrotomed using a diamond knife at $-140^{\circ} \mathrm{C}$. The nominal section thickness was $100 \mathrm{~nm}$. The samples were observed on a JEOL JEM 1230 Transmission Electron Microscope, operating at $80 \mathrm{kV}$.

Small-angle neutron scattering (SANS) were collected using the equipment PACE provided by the Laboratoire Léon Brillouin at Saclay (France). A wavelength between 4 and $20 \AA$ can be used with a wavelength spread of $\Delta \lambda / \lambda=0.10$ and a sample-todetector distance between 1 to $5 \mathrm{~m}$. The scattering vector $q$, ranges between $3 \cdot 10^{-3}$ and $0.3 \AA^{-1}$.

Strips of unfilled and filled elastomers were used in the uniaxial elongation experiments carried out to obtain the stress-strain curves at equilibrium [18]. The nominal stress $\sigma$, was calculated from Equation (3):

$$
\sigma=\frac{f}{A}
$$

where $f$ is the elastic force and $A$ is the undeformed cross-sectional area and the reduced stress, $\sigma^{*}$ was calculated from Equation (4):

$$
\sigma^{*}=\frac{\sigma}{\alpha-\alpha^{-2}}
$$

where $\alpha$ is the extension ratio (ratio of the final length of the sample in the direction of stretch to the initial length before deformation).

To determine the equilibrium swelling of the vulcanizate, a sample of $20 \mathrm{~mm} \times 10 \mathrm{~mm} \times 1 \mathrm{~mm}$ was put into toluene. After $72 \mathrm{~h}$ at room temperature, the sample was taken out of the liquid, the toluene removed from the surface and the weight determined. The swelling ratio, $Q$, was also determined from the lengths of the sample in the unswollen and swollen states.

\section{Results and discussion}

\subsection{Filler characterization}

Microscopy and scattering techniques are very useful for the characterization of generated filler structures. For filled materials formed by swelling an elastomeric network in alkoxides and subsequently polymerizing by the sol-gel technique, the generated particles are usually more finely dispersed than those prepared by a physical blending of preformed filler particles into polymers.

Figure 1 show TEM images of composites filled with $\mathrm{SiO}_{2}$ (Figure 1a and 1b) or $\mathrm{TiO}_{2}$ (Figure 1c -1 e) particles in situ generated in already-formed PDMS networks. But although in situ precipitated filler particles seem to be uniformly dispersed in both cases, different morphologies are revealed. The diameter of the generated silica particles is seen to be much smaller than that of titanium dioxide particles. The composite containing $10 \mathrm{phr}$ of $\mathrm{SiO}_{2}$ (Figure 1a) shows an excellent dispersion of the mineral phase in the polymer with small silica domains around $\sim 5 \mathrm{~nm}$ in diameter and rather diffuse interfaces. For the higher content, a fine morphology of the silicate structure is still obtained suggesting an interpenetrated polymer-silica structure and the sample may be regarded as microscopically phase separated but macroscopically uniform. TEM images of titania-filled PDMS composites indicate an obvious two-phase structure with particles approximately spherical in shape and 


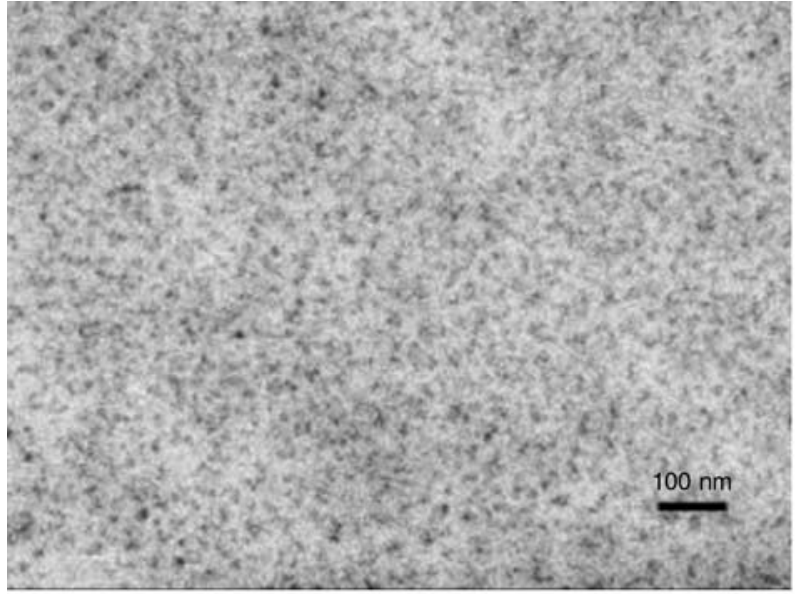

a)

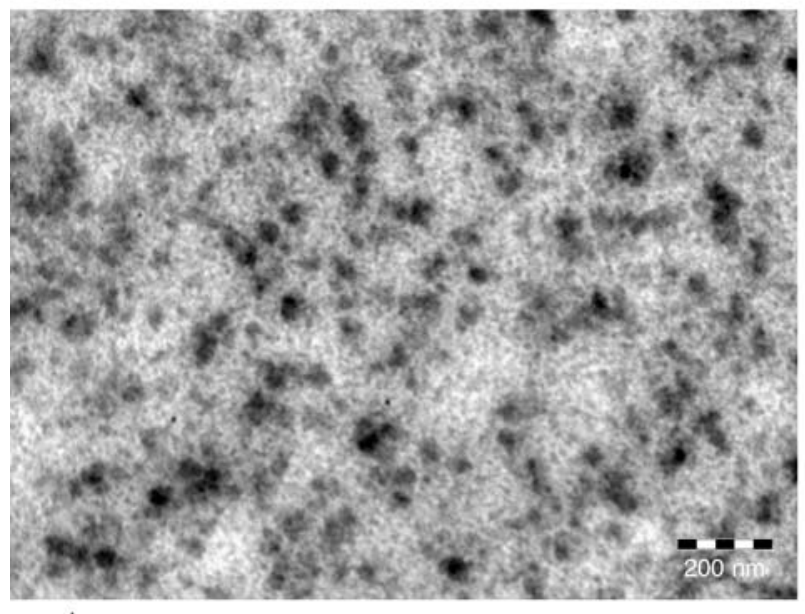

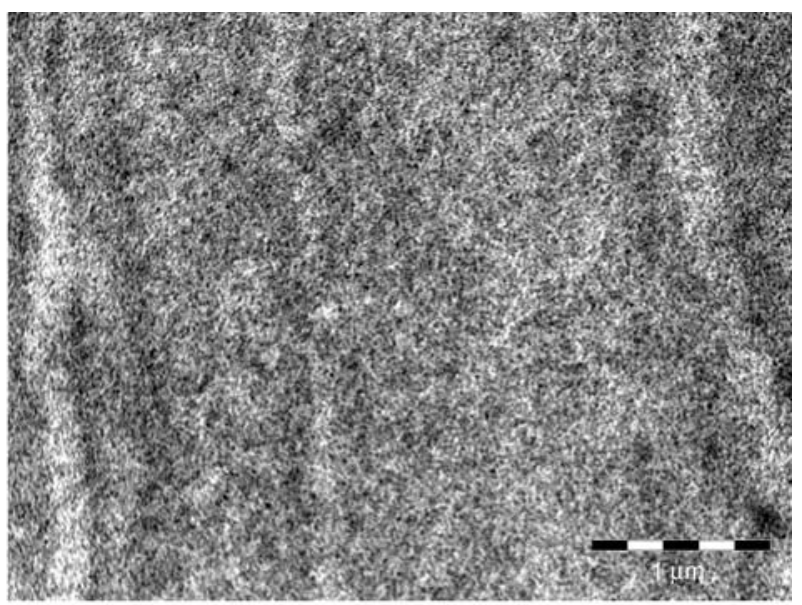

b)

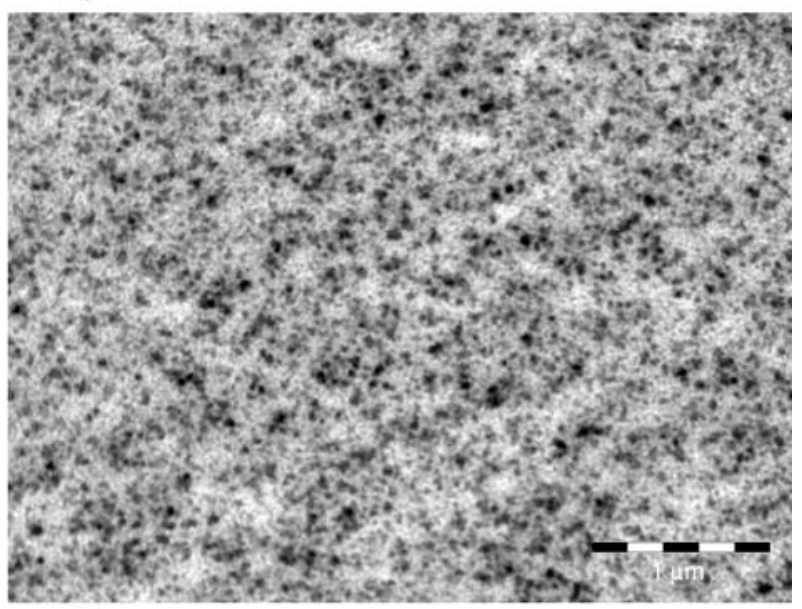

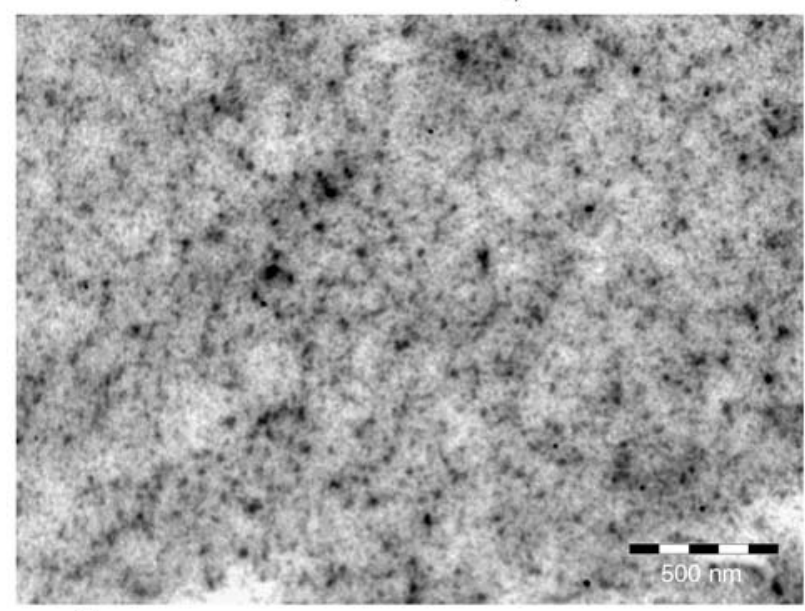

e)

Figure 1. TEM images of PDMS composites filled with in situ generated particles: a) $10 \mathrm{phr}$ of $\mathrm{SiO}_{2}$, b) $28 \mathrm{phr}$ of $\mathrm{SiO}_{2}$, c) $12 \mathrm{phr}$ of $\mathrm{TiO}_{2}$, d) $12 \mathrm{phr}$ of $\mathrm{TiO}_{2}$, e) $25 \mathrm{phr}$ of $\mathrm{TiO}_{2}$

diameters between 20 and $40 \mathrm{~nm}$ in size. The interface between the polymer and the particles is better defined than in the case of silica-filled systems and even at the lowest filler content (Figure 1c and 1d), the titania particles are almost connected in a branched network structure.
With the aid of concepts in fractal geometry, some aspects of the filler structure can be derived from small-angle scattering techniques. The scattering profiles of fractal objects are a power law of the type described by Equation (5):

$$
I(q)=q^{-P}
$$


where $I$ is the scattered intensity at wave vector $q$ and the exponent $P$ allows to distinguish between mass and surface fractals $[9,10,19]$. A slope of -4 in log-log axes, indicates that the system follows the Porod's law $\left(P=D_{s}-6\right), D_{s}$ being the surface fractal dimension. The scatterers are, in this case, dense objects characterized by smooth surface fractal dimension $\left(D_{s}=2\right)$. A value of $P$ between -3 and -4 , is indicative of compact objects with fractally rough surfaces. If $P<3$, scatterers are mass fractal objects with a fractal dimension $D_{f}=P$. A slope of -2 suggests the presence of a polymeric structure.

As seen in Figure 2, the two types of composites yield distinctive small-angle scattering profiles. The slope of 3.3 obtained for the $\mathrm{PDMS} / \mathrm{TiO}_{2}$ composite indicated that the system is close to the Porod's law with uniformly dense objects characterized by almost rough surface fractal dimension. A correlation peak, observed at about $0.035 \AA$, associated with a characteristic length, $L_{c o r}$ of about $18 \mathrm{~nm}$ is observed for the silica-filled compound. In a previous study [7], the maximum of the correlation peak has been shown to shift to smaller $q$ with the amount of filler. In our synthetic protocol, silica formation takes place in a swollen network, the network swelling ratio in TEOS, $Q$, determining the amount of filler. So the mean-squared endto-end distance of a network chain in the swollen state, $\left\langle r^{2}\right\rangle^{1 / 2}{ }_{s w}$ can been correlated to the swelling ratio $Q$ through the Equation (6):

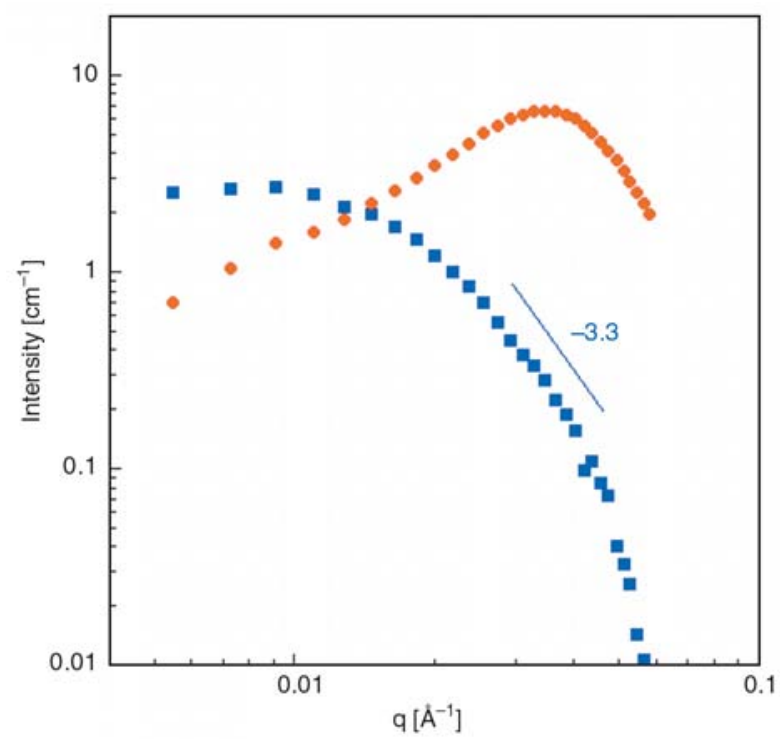

Figure 2. Small-angle neutron scattering of composites filled with 22 phr of generated particles: $\mathrm{SiO}_{2}$ $(\bullet) ; \mathrm{TiO}_{2}(\mathbf{\square})$
$<r^{2}>_{\mathrm{sw}}=Q^{2 / 3}<r^{2}>_{0}=Q^{2 / 3} C_{\infty} n l^{2}$

where $C_{\infty}$ is the characteristic ratio of a chain of $n$ bonds of length $l$ and $\left\langle r^{2}\right\rangle_{0}$ is the mean-squared end-to-end distance of a network chain in the unperturbed state.

A linear dependence of $L_{c o r}$ with $\left\langle r^{2}\right\rangle^{1 / 2}$ sw has been found [7] which has led to the belief that the network itself imposes a length scale on the growth of the generated particles.

\subsection{Stress-strain behavior}

According to the different morphologies deduced from TEM and SANS, one would predict different mechanical properties for the two types of composites. As revealed in Figure 3a, a quite different tensile behavior is observed. At small strains, a higher level of reinforcement is obtained for the titaniafilled sample while at higher strains, the silicafilled sample displays a sharp increase in stress. Plots of the reduced stress, $\sigma^{*}$ against reciprocal elongation, are presented in Figure 3b. They show a marked decrease in stress attributed to the breakdown of the filler network upon application of the deformation and an upturn in modulus at high elongations for the $\mathrm{PDMS} / \mathrm{SiO}_{2}$ composite. The existence of a titania network even at low filler contents has been already revealed by TEM images. The upturn in the modulus observed in the silica-filled compound is attributed to non-Gaussian effects arising from the limited extensibilities of the network chains. It is somewhat the signature of a strong polymer-filler interface resulting from the interaction between the silanols present on the silica surface and the PDMS chains. On the other hand, the excellent dispersion as well as the small size of the particles offer a large interfacial area available for polymer-filler interactions. The $\mathrm{PDMS} / \mathrm{TiO}_{2}$ composite does not exhibit the upturn in the modulus which reflects less interfacial adhesion between the filler particles and the polymer chains. At large deformations, the mechanical behavior of the titania-filled composite is close to that of a thermoplastic polymer with a smaller strain dependence of the stress. This plastics-like stress-strain curve is probably related to the deformation of polymer chains confined between filler particles. These network chains, which are immobilized, behave as hard filler. 

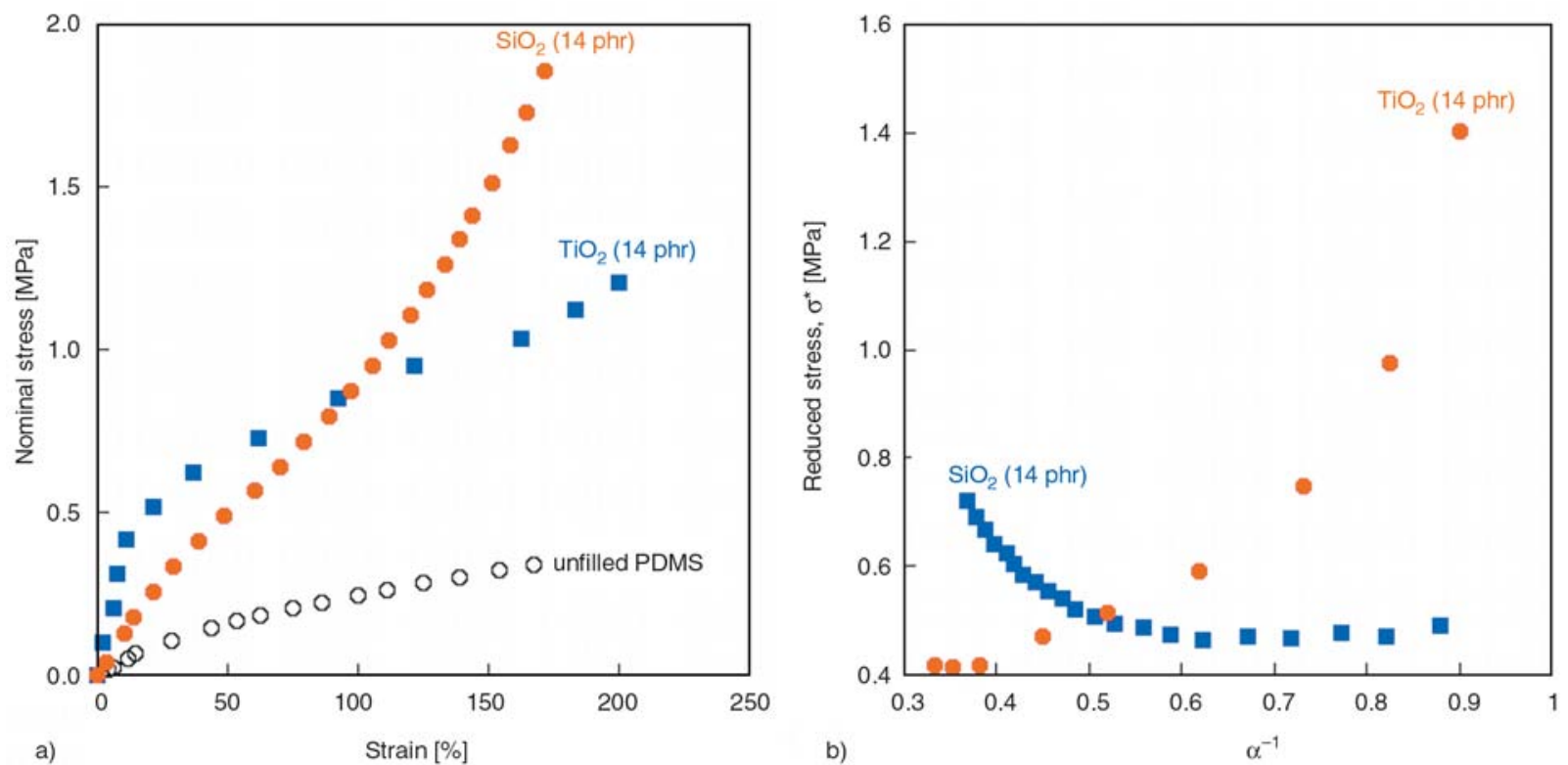

Figure 3. Comparison of the tensile behavior of PDMS composites containing a same amount of filler
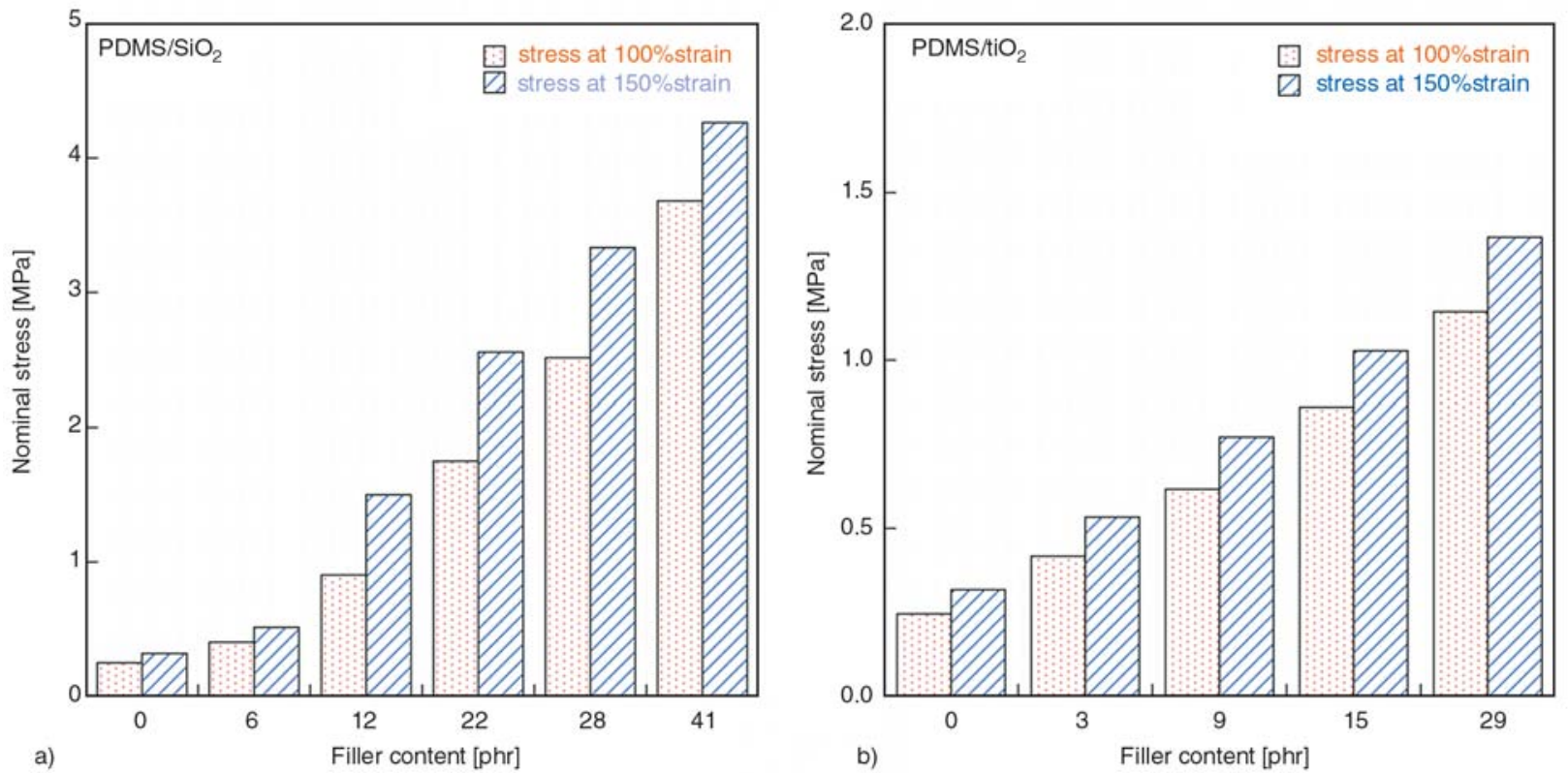

Figure 4. Tensile tests of the PDMS composites as a function of the amount of filler

Figure 4 shows the dependence of the stress at 100 and $150 \%$ strain on the amount of filler. The moduli of the composites are found to increase significantly with increase in amount of either type of filler with larger reinforcing effects at high elongations in the case of silica.

\subsection{Swelling measurements}

Besides the increase in the elastic modulus, another characteristic feature of filler reinforcement is a reduction in the ability of filled vulcanizates to swell in solvents. This restriction of swelling has been associated with the degree of interaction between rubber and filler. More generally, the swelling procedure has been applied in filled vulcanizates to evaluate the number the total network chain density $\mathrm{v}\left(\mathrm{v}=\mathrm{v}_{r}+\mathrm{v}_{f}\right.$, where $\mathrm{v}_{r}$ is the number of effective network chains in the unfilled rubber, and $v_{f}$ is the number of additional chains produced by the bonding to the filler). This number, $v_{f}$, of filler-rubber attachments is expected to be strongly dependent of the surface chemistry of the reinforcing filler. The advantage of the swelling measurements over the use of stress-strain measurements for estimating additional cross-linking provided by 
the presence of filler is that they are free from hydrodynamic reinforcement.

Under the assumption that the filler particles do not swell, one can calculate the equilibrium swelling ratio of the rubber phase, $Q_{r}$ (see Equation (7)), from the equilibrium swelling ratio, $Q$ of the composite $\left(Q=V / V_{d}, V\right.$ being the volume of the sample plus solvent and $V_{d}$ that of the dry sample) and the volume fraction of filler, $\phi$ :

$Q_{r}=\frac{Q-\phi}{1-\phi}$

According to Kraus [20, 21], the swelling for a large number of vulcanizates containing highly reinforcing fillers has been found to obey Equation (8):

$\frac{Q_{r}}{Q_{r 0}}=\frac{v_{r 0}}{v_{r}}=1-\frac{m \phi}{1-\phi}$

where $Q_{r}$ and $Q_{r 0}$ are the rubber equilibrium swelling ratios for the filled and unfilled samples, respectively, $v_{r 0}$ is the volume fraction of the unfilled rubber after swelling, $v_{r}$ is the volume fraction of rubber in the gel of the filled vulcanizate after swelling and $m$ is defined by Equation (9):

$m=3 c\left(1-v_{r 0} 1 / 3\right)+v_{r 0}-1$

$c$ is a constant characteristic of the filler, but independent of the polymer, the solvent or the degree of vulcanization. This parameter arises from the man-

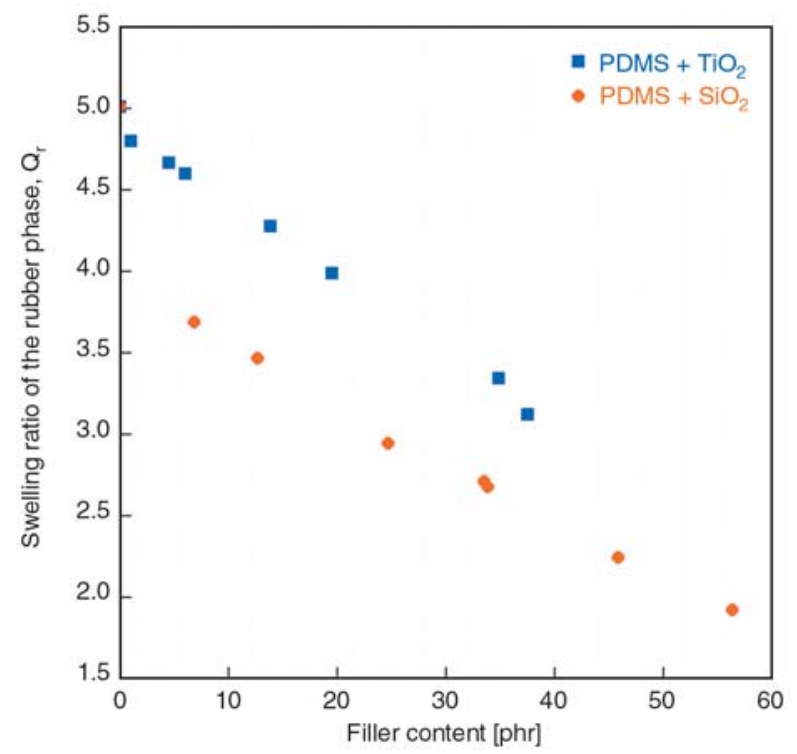

Figure 5. Dependence of rubber phase swelling on the amount of filler

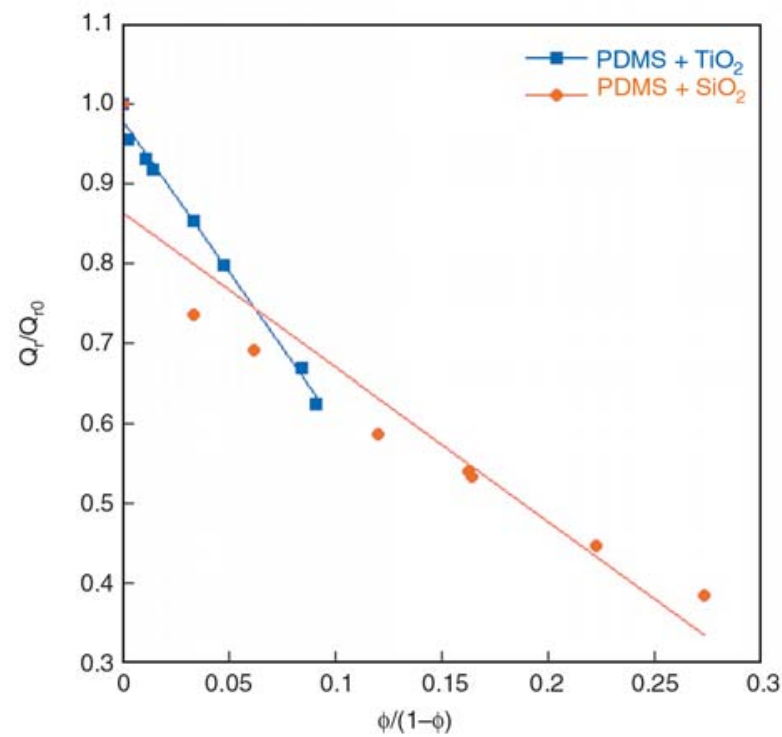

Figure 6. Plot of $Q_{r} / Q_{r}$ against filler loading expressed as volume ratio of filler to rubber

ner in which the local restriction of swelling varies with the distance from the surface.

Figure 5 displays the equilibrium swelling ratio of the rubber phase in toluene, $Q_{r}$. For each type of composite, $Q_{r}$ decreases with the amount of filler, indicating a pronounced restriction in swelling in the filled samples. Nevertheless, at a given filler loading, $Q_{r}$ is higher for the titania-filled samples reflecting less polymer-filler linkages. Representation of Equation (8) is reported in Figure 6 and leads to slopes equal to 1.9 and 3.8 for $\mathrm{SiO}_{2}$ and $\mathrm{TiO}_{2}$, respectively. Values of the parameter $c$ equal to 2.2 and 3.7 respectively can be extracted from the slopes according to Equation (9). The larger value obtained in samples filled with titania shows that restriction of swelling is extended to a larger distance from the particle surface with regard to silica analogs. This interpretation is consistent with the existence of confined polymer chains between titania particles as discussed in the previous section.

\section{Conclusions}

The usual sol-gel technique for the in situ precipitation of reinforcing particles within an elastomer is applied for the generation of silica and titania as an extension of preliminary studies reported earlier. The two types of particles exhibit two distinct morphologies, two different polymer-filler interfaces 
that influence the mechanical properties of the resulting materials.

Although all composites have mechanical properties that are very much improved compared to the unfilled network, the two types of particles impart to the resulting materials a quite different tensile behavior. The high level of stress obtained at small deformations for the titania-filled PDMS reflects the formation of a filler network at a relatively low filler content. On the other hand, the low strain dependence of the stress and the absence of upturn in modulus at large deformations lead to the belief that $\mathrm{TiO}_{2}$ is less interacting with the elastomeric phase and the polymer chains are confined between filler particles.

\section{References}

[1] Wang S., Xu P., Mark J. E.: Shear and biaxial extension measurements of reinforcement form in-situ precipitated silica. Rubber Chemistry and Technology, 64, 746-759 (1991).

[2] Wen J., Mark J. E.: Precipitation of silica-titania mixed-oxide fillers into poly(dimethylsiloxane) networks. Rubber Chemistry and Technology, 67, 806819 (1994)

[3] Wang S-B., Mark J. E.: In-situ precipitation of reinforcing titania fillers. Polymer Bulletin, 17, 271-277 (1987).

DOI: $10.1007 / \mathrm{BF} 00285360$

[4] Whang C. M., Yeo C. S., Kim Y. H.: Preparation and characterization of sol-gel derived $\mathrm{SiO}_{2}-\mathrm{TiO}_{2}-\mathrm{PDMS}$ composite films. Bulletin of the Korean Chemical Society, 22, 1366-1370 (2001).

[5] Rajan G. S., Sur G. S., Mark J. E., Schaefer D. W., Beaucage G.: Preparation and characterization of some unusually transparent poly(dimethylsiloxane) nanocomposites. Journal of Polymer Science Part B: Polymer Physics, 41, 1897-1901 (2003). DOI: $10.1002 /$ polb.10565

[6] Murugesan S., Sur G. S., Mark J. E., Beaucage G.: Insitu catalyst generation and controlled hydrolysis in the sol-gel precipitation of zirconia and titania particles in poly(dimethylsiloxane). Journal of Inorganic and Organometallic Polymers, 14, 239-252 (2004). DOI: $10.1023 / \mathrm{B}:$ JOIP.0000048029.08289.fe

[7] Dewimille L., Bresson B., Bokobza L.: Synthesis, structure and morphology of poly(dimethylsiloxane) networks filled with in situ generated silica particles. Polymer, 46, 4135-4143 (2005). DOI: $10.1016 /$ j.polymer.2005.02.049

[8] Mark J. E.: Novel reinforcement techniques for elastomers. Journal of Applied Polymer Science: Applied Polymer Symposium, 50, 273-282 (1992).
[9] McCarthy D. W., Mark J. E., Schaeffer D. W.: Synthesis, structure, and properties of hybrid organicinorganic composites based on polysiloxanes. I. Poly(dimethylsiloxane) elastomers containing silica. Journal of Polymer Science Part B: Polymer Physics, 36, 1167-1189 (1998).

DOI: 10.1002/(SICI)1099-0488(199805)36:7<1167:: AID-POLB7>3.0.CO;2-R

[10] McCarthy D. W., Mark J. E., Clarson S. J., Schaeffer D. W.: Synthesis, structure, and properties of hybrid organic-inorganic composites based on polysiloxanes. II. Comparisons between poly(methylphenylsiloxane) and poly(dimethylsiloxane), and between titania and silica. Journal of Polymer Science Part B: Polymer Physics, 36, 1191-1200 (1998).

DOI: 10.1002/(SICI)1099-0488(199805)36:7<1191:: AID-POLB8>3.0.CO;2-X

[11] Breiner J. M., Mark J. E., Beaucage G.: Dependence of silica particle sizes on network chain lengths, silica contents, and catalyst concentrations in in situ-reinforced polysiloxane elastomers. Journal of Polymer Science Part B: Polymer Physics, 37, 1421-1427 (1999).

DOI: $10.1002 /($ SICI $) 1099-0488(19990701) 37: 13$ $\leq 1421:$ AID-POLB8>3.0.CO;2-M

[12] Yuan Q. W., Mark J. E.: Reinforcement of poly(dimethylsiloxane) networks by blended and insitu generated silica fillers having various sizes, size distributions, and modified surfaces. Macromolecular Chemistry and Physics, 200, 206-220 (1999).

DOI: 10.1002/(SICI)1521-3935(19990101)200:1 $\leq 206:$ :AID-MACP206>3.0.CO;2-S

[13] Takeuchi H., Cohen C.: Reinforcement of poly(dimethylsiloxane) elastomers by chain-end anchoring to clay particles. Macromolecules, 32, 6792-6799 (1999).

DOI: $10.1021 / \mathrm{ma} 990218+$

[14] Schmidt D. F., Clément F., Giannelis E. P.: On the origins of silicate dispersion in polysiloxane/layered silicate nanocomposites. Advanced Functional Materials, 16, 417-425 (2006). DOI: $\underline{10.1002 / \mathrm{adfm} .200500008}$

[15] Bradley D. C., Mehrotra R. C., Gaur D. P.: Metal alkoxides. Academic Press, London (1986).

[16] He Y-q., Ping Y-h.: Nano-composite $\mathrm{TiO}_{2}$-PI via solgel process. Materials Chemistry and Physics, 78, 614-619 (2003). DOI: $\underline{10.1016 / \mathrm{S} 0254-0584(02) 00118-9}$

[17] Xiong M., Zhou S., You B., Gu G., Wu L.: Effect of preparation of titania sol on the structure and properties of acrylic resin/titania hybrid materials. Journal of Polymer Science Part B: Polymer Physics, 42, 3682 3694 (2004). DOI: $10.1002 /$ polb.20218 
[18] Bokobza L., Rahmani M., Belin C., Bruneel J-L., El Bounia N-E.: Blends of carbon blacks and multiwall carbon nanotubes as reinforcing fillers for hydrocarbon rubbers. Journal of Polymer Science Part B: Polymer Physics, 46, 1939-1951 (2008).

DOI: $10.1002 /$ polb.21529

[19] Breiner J. M., Mark J. E.: Preparation, structure, growth mechanisms and properties of siloxane composites containing silica, titania or mixed silica-titania phases. Polymer, 39, 5483-5493 (1998).

DOI: $10.1016 / \mathrm{S} 0032-3861(97) 10276-2$
[20] Kraus G.: Interactions between elastomers and reinforcing fillers. in 'Reinforcement of elastomers' (ed.: Kraus G.) New York, Wiley, 125-152 (1965).

[21] Kraus G.: Reinforcement of elastomers by carbon black. Advances in Polymer Science, 8, 155-237 (1971).

DOI: $10.1007 / 3-540-05483-9 \quad 12$ 